\title{
Plasma lipoproteome in Alzheimer's disease: a proof-of-concept study
}

\author{
Danni Li ${ }^{1 *}$, Fangying Huang ${ }^{1}$, Yingchun Zhao ${ }^{2}$, Peter W. Villata ${ }^{2}$, Timothy J. Griffin ${ }^{3}$, Lin Zhang ${ }^{4}$, Ling Li ${ }^{5+}$ \\ and Fang $Y^{6+}$
}

\begin{abstract}
Background: Although total plasma lipoproteome consists of proteins that have shown promises as biomarkers that can identify Alzheimer's disease (AD), effect sizes are modest. The objective of this study is to provide initial proof-ofconcept that the plasma lipoproteome more likely differ between AD cases and controls when measured in individual plasma lipoprotein fractions than when measured as total in immunodepleted plasma.

Methods: We first developed a targeted proteomics method based on selected reaction monitoring (SRM) and liquid chromatography and tandem mass spectrometry for measurement of 120 tryptic peptides from 79 proteins that are commonly present in plasma lipoproteins. Then in a proof-of concept case-control study of 5 AD cases and 5 sex- and age-matched controls, we applied the targeted proteomic method and performed relatively quantification of 120 tryptic peptides in plasma lipoprotein fractions (fractionated by sequential gradient ultracentrifugation) and in immunodepleted plasma (of albumin and lgG). Unadjusted p values from two-sample t-tests and overall fold change was used to evaluate a peptide relative difference between AD cases and controls, with lower $p$ values $(<0.05)$ or greater fold differences (> 1.05 or $<0.95$ ) suggestive of greater peptide/protein differences.
\end{abstract}

Results: Within-day and between-days technical precisions (mean \%CV [SD] of all SRM transitions) of the targeted proteomic method were 3.95\% (2.65) and 9.31\% (5.59), respectively. Between-days technical precisions (mean \% CV [SD]) of the entire plasma lipoproteomic workflow including plasma lipoprotein fractionation was $27.90 \%$ (14.61). Ten tryptic peptides that belonged to 5 proteins in plasma lipoproteins had unadjusted $p$ values $<0.05$, compared to no peptides in immunodepleted plasma. Furthermore, 27, 32, 17, and 20 tryptic peptides in VLDL, IDL, LDL and $\mathrm{HDL}$, demonstrated overall peptide fold differences $>1.05$ or $<0.95$, compared to only 6 tryptic peptides in immunodepleted plasma. The overall comparisons, therefore, suggested greater peptide/protein differences in plasma lipoproteome when measured in individual plasma lipoproteins than as total in immunodepleted plasma. Specifically, protein complement C3's peptide IHWESASLLR, had unadjusted p values of $0.00007,0.00012$, and 0.0006 and overall $1.25,1.17,1.14$-fold changes in VLDL, IDL, and LDL, respectively. After positive False Discovery Rate (pFDR) adjustment, the complement C3 peptide IHWESASLLR in VLDL remained statistically different (adjusted $p$ value $<0.05$ ).

Discussion: The findings may warrant future studies to investigate plasma lipoproteome when measured in individual plasma lipoprotein fractions for AD diagnosis.

Keywords: Alzheimer's disease, Plasma lipoproteins, Targeted proteomics, Complement C3, Very low-density lipoprotein (VLDL), Intermediate density lipoprotein (IDL), Low density lipoprotein (LDL), High-density lipoprotein (HDL), Biomarker, Diagnosis, Selected reaction monitoring (SRM)

\footnotetext{
*Correspondence: dannili@umn.edu

${ }^{\dagger}$ Ling Li and Fang Yu: Co-senior author

1 Department of Laboratory Medicine and Pathology, University

of Minnesota, 420 Delaware Street SE, MMC 609, Minneapolis, MN 55455,

USA

Full list of author information is available at the end of the article
} 


\section{Background}

Tremendous work has taken place to identify AD biomarkers, especially using cerebrospinal fluid (CSF) and neuroimaging approaches $[1,2]$. However, these CSF and neuroimaging biomarkers are appropriate for research purpose only and their use in a primary care clinical setting are limited due to safety concerns, costs, and requirements for specialized skills/facilities, which have and will continue to constraint the clinical use of these biomarkers. In contrast, blood-based biomarkers represent a clinically applicable alternative that would be both cost-effective and minimally invasive, ideal for wide clinical adoption $[1,2]$. Plasma lipoproteome such as apolipoproteins E and J (Apo E and Apo J) play important roles in the pathophysiological development of $\mathrm{AD}$ and are promising blood-based biomarkers for early AD detection $[3,4]$. Low levels of plasma Apo E and high levels of plasma Apo J have been associated with brain amyloidosis [4], hippocampal atrophy $[4,5]$, cognitive decline [6], and incident dementia (including AD) [7, 8]. However, effect sizes of the reported associations have been modest, which raises questions regarding their clinical significance in diagnosing $\mathrm{AD}[4,7]$. For instance, high plasma Apo J only increased AD diagnostic accuracy by $8 \%$ over age, sex, and $A P O E$ genotype alone [4]. To address this issue, a methodological approach to increase the diagnostic value of plasma lipoproteome is to discern individual plasma lipoprotein classes and fractionate plasma prior to analysis. This is because the total plasma lipoproteome are unevenly distributed across four major plasma lipoproteins (very low-density lipoprotein [VLDL], intermediate density lipoprotein [IDL], low density lipoprotein $[\mathrm{LDL}]$, and high-density lipoprotein [HDL]) $[9,10]$. Discerning plasma lipoproteome in individual plasma lipoprotein classes may help uncover their unique relations with $\mathrm{AD}$ that would not otherwise be identifiable with total plasma lipoproteome.

The objectives of this proof-of-concept study are twofold. First is to establish a plasma lipoproteomic workflow that includes a targeted proteomic method based on selected reaction monitoring (SRM) and liquid chromatography and tandem mass spectrometry (LC/MS/ MS) to perform relative quantitative peptide analyses in all 4 fractionated plasma lipoproteins (VLDL, IDL, LDL, HDL). Using a Fit-for Purpose approach, this targeted proteomic method is designed to be a "Tier 3" targeted peptide measurement, which is best suited for exploratory and discovery studies and only include limited isotope labelled reference peptides (not for every peptide) $[11,12]$. More importantly, this study is designed to provide initial proof-of-concept that plasma lipoproteome more likely differs between AD cases (diagnosed based on clinical examination only) and controls when measured in individual plasma lipoprotein fractions than measured as total in immunodepleted plasma.

\section{Methods \\ Reagents}

ProteoPrep Immunoaffinity Albumin and IgG Depletion Kit was obtained from Sigma Aldrich (St. Louis, MO). All reagents were obtained from Thermo Fisher Scientific if not otherwise indicated. Water and acetonitrile (ACN) were Optima LC/MS grade. Isotopically labelled tryptic peptide standards DLLSPR (+6 Da mass shift for L, Fibrinogen), LGPLVEQGR (+6 Da mass shift for $\mathrm{L}$ and +3 Da for G, ApoE), TYLPAVDEK (+6 Da mass shift for $L, A p o C 2)$, and YLYAR ( 6 Da mass shift for $L$, SAA4) were synthesized locally in at the UMN (Dr. Laura Parker's lab), and prepared in standard stocks with concentration of $1 \mathrm{mM}$ in $20 \% \mathrm{ACN}$ and $0.1 \%$ formic acid (FA). These four tryptic peptide standards were selected based from empirically obtained data. In the proteomic sample preparation described later, the peptide standards were added to trypsin digested peptides before desalting using stage tips that were made in-house using $200 \mu \mathrm{L}$ pipette tips with $3 \mathrm{M}$ (St. Paul, MN) Empore ${ }^{\mathrm{TM}}$ solid phase extraction disks styrenedivinylbenzene-reversed phase sulfonate (SDB-RPS) (Saint Paul, MN).

\section{Plasma samples}

Ten fasting EDTA plasma samples were obtained from 5 $\mathrm{AD}$ cases and 5 age- and sex-matched controls. These 5 AD cases were from the FIT-AD Trial [13], in which AD dementia was diagnosed based on clinical evaluations only. These 5 controls were community dwelling subjects without dementia whose samples were purchased from the Solomon Park Research Laboratories and were requested to be processed in the same ways as samples of AD cases in the FIT-AD Trial. Details of blood collection and processing protocols are included in Additional file 1. All the plasma samples were stored at a $-80{ }^{\circ} \mathrm{C}$ freezer. This study was reviewed and approved by the University of Minnesota (UMN) Institutional Review Board.

\section{Fractionation of plasma lipoproteins}

"Frozen never thawed" plasma aliquots were thawed and fractionated into 4 plasma lipoprotein classes (VLDL, IDL, LDL, and HDL) using a sequential gradient ultracentrifugation protocol with modifications [14]. Please see the protocol details in Additional file 1. All fractions were divided into small aliquots and stored at $-80{ }^{\circ} \mathrm{C}$ until further analysis.

\section{Immunoaffinity depletion}

The aforementioned thawed plasma underwent albumin and IgG depletion by using the commercial ProteoPrep 
Immunoaffinity Albumin and IgG Depletion Kit per manufacturer's instructions. Please see the protocol details in Additional file 1.

\section{Proteomics sample preparation}

VLDL, IDL, LDL, HDL fractions and immunodepleted plasma samples (only depleted of albumin and IgG), each of $60 \mu \mathrm{L}$, underwent a delipidation protocol to remove lipids and extract proteins [15]. After delipidation, resulted protein pellets were re-suspended in a denaturing buffer (8 $\mathrm{M}$ urea and $0.4 \mathrm{M}$ ammonia bicarbonate). Protein concentrations in the VLDL, IDL, LDL, HDL and plasma samples were determined using the BCA Protein Assay kit. The amount of proteins used for subsequent proteomics sample preparation for VLDL, IDL, LDL, HDL and plasma were $6.5,3,3,10$, and $10 \mu \mathrm{g}$, respectively. Protein samples were reduced using $10 \mathrm{mM}$ TCEP (final concentration), alkylated using $12 \mathrm{mM}$ iodoacetamide (final concentration), and trypsin digested (protein to trypsin mass ratio was $50: 1$ ) at $37{ }^{\circ} \mathrm{C}$ overnight. Trypsin digestion activity in the samples was stopped by freezing them for $20 \mathrm{~min}$ at $-80{ }^{\circ} \mathrm{C}$. The four isotope labeled tryptic peptide standards were added to each sample (a final concentration of $50 \mathrm{nM}$ per peptide in IDL, LDL, HDL, and immunodepleted plasma samples and of $67 \mathrm{nM}$ in VLDL), which were dried down using speed vacuum for about $3 \mathrm{~h}$. The resulted dried samples were reconstituted in a buffer of $2 \% \mathrm{ACN}$ and $0.1 \% \mathrm{FA}$ to reach the final concentration of $0.5 \mathrm{mg} / \mathrm{mL}$ (based on starting amount of proteins $10 \mu \mathrm{g}$ and zero loss) and then desalted using a stage-tip protocol (Additional file 1).

Targeted proteomics analysis based on SRM and LC/MS/MS Two microliters of each of the desalted peptide samples were injected onto a home-packed analytical C18 reverse phase column $(75 \mu \mathrm{m}$ ID $\times 200 \mathrm{~mm}, 10 \mu \mathrm{m}$ emitter orifice, Luna C18 $5 \mu \mathrm{m}$ particles [Phenomenex, Torrance, CA]). Peptides were eluted with buffer A (0.1\% FA in water) and buffer B (0.1\% FA in ACN) with the following gradient profile: $0-17 \mathrm{~min}, 2 \% \mathrm{~B}$ flow rate at $0.3 \mu \mathrm{L} / \mathrm{min}$; $17-77 \mathrm{~min}, 2-45 \% \mathrm{~B}$ at $0.3 \mu \mathrm{L} / \mathrm{min}$; $77-78 \mathrm{~min}, 45-90 \%$ $\mathrm{B}$ at $0.3 \mu \mathrm{L} / \mathrm{min}$ to $1 \mu \mathrm{L} / \mathrm{min} ; 78-81 \mathrm{~min}, 90 \% \mathrm{~B}$ at $1 \mu \mathrm{L} /$ min; $81-82 \mathrm{~min}, 90-2 \%$ B at $1 \mu \mathrm{L} / \mathrm{min}$; $82-87 \mathrm{~min}, 2 \% \mathrm{~B}$ at $1 \mu \mathrm{L} / \mathrm{min}$. Mass spectrometry detection was obtained on a TSQ Quantiva Triple Quadrupole (Thermo Scientific) in positive nanospray ionization mode. The mass spectrometry conditions were: spray voltage $2.0 \mathrm{kV}$, ion transfer tube temperature $350{ }^{\circ} \mathrm{C}$, with collision energy in the range of $14.1 \mathrm{~V}$ to $42.2 \mathrm{~V}$ and a collision gas (argon) pressure of 1 mTorr. The resolution settings were $0.7 \mathrm{Da}$ (full width at half-maximum) for both quadrupoles and transition dwell times were $10 \mathrm{~ms}$.

\section{Peptide relative quantification}

Skyline (version 3.6, 10493), an open source software, was used for quantitative data processing and proteomic analysis [16]. Specifically, Skyline was used to inspect peak integration and export integrated peak area along with other information such as background peak area. All integrated peaks were manually inspected to ensure correct peak detection, and integration was adjusted if necessary. To calculate relative peptide levels, background peak area was subtracted from total peak area of each SRM transition to calculate corrected peak area of all the SRM transitions including those for the peptide standards. Then, all the SRM transitions of the peptide standards in each sample were summed and used to normalize differences across all the samples due to variations in peptide analyses so that so the sums for every sample were equal. Then peak areas of 3 SRM transitions of a peptide was averaged to calculate its relative level.

\section{Statistical analysis}

The relative level of each peptide was log-transformed (after adjustment of internal standards and batch effect if any), and two-sample t-tests were used to compare a peptide level between AD cases and controls. Fold changes were calculated as ratios of log-transformed relative level of a peptide between controls and AD cases. Furthermore, to account for multiple comparison testing, $p$ values were adjusted using the method of positive False Discovery Rate (pFDR) [17]. Sample size and power considerations for future studies were also performed. Excel, $\mathrm{R}$, and Graphpad Prism were used for data analysis.

\section{Results}

\section{The targeted proteomics method}

We developed a "Tier-3" targeted proteomic method [11] based on SRM and LC/MS/MS to perform relative quantitative analyses of 120 trypsin-digested peptides from 79 proteins present in plasma lipoproteins. This method included 4 isotope labeled peptides added after trypsin digestion to normalize variations in peptide analyses (e.g., desalting and LC/MS/MS analysis). To develop this targeted proteomic method, we had first performed shotgun proteomic experiments and identified plasma lipoproteins present in VLDL, IDL, LDL, and HDL. Then we used the shotgun proteomics data in combination the information available from the PeptideAltas spectral library to select proteins and tryptic peptides (i.e., trypsin enzyme only cleaves peptide chains at the carboxyl side of the amino acid lysine or arginine, except when either is followed by proline) which were subjected to Skyline for create a list of in silico SRM transitions. Briefly, 51 proteins were selected based on at least 2 tryptic peptide 
spectra available in our own spectral library (the shotgun proteomics data); and another 58 proteins were selected based on at least 1 tryptic peptide spectra available from our own spectral library (the rest tryptic peptides were selected from the PeptideAtlas spectral library to make 2-5 tryptic peptides per protein). Then, Skyline was used to select 5 transitions for each tryptic peptide. These in silico SRM transitions were further empirically tested using a sample mixed with equal amounts of tryptic peptides from VLDL, IDL, LDL, and HDL, which resulted in 79 proteins and 120 peptides, each protein with 1-3 signature peptide and each peptide of 3 SRM transitions. The selection of signature tryptic peptides was based on criteria reported previously [18-20]. Furthermore, we also empirically determined 3 SRM transitions for the 4 isotope labelled peptide standards. Additional file 2: Table S1 shows the list of 79 proteins and peptides selected for targeted analyses by SRMs, as well as precursor/fragment transition pairs and corresponding collision energies.

Within-day and between-days technical precisions of this targeted proteomic method (calculated as mean [SD] CVs \% of all the 120 SRM transitions), evaluated by repeated measurement of a sample (mixed with equal weight of peptides from VLDL, IDL, LDL, and HDL) three times within a day $(\mathrm{n}=3)$ and three times across three days $(n=3)$, were $3.95 \%$ (2.65) and 9.31\% (5.59), respectively.

\section{Plasma lipoproteomics versus plasma proteomics}

Figure 1 illustrates total and fractionated plasma lipoproteomic work flows that every plasma went through before analysis by the targeted proteomic method. The total plasma lipoproteomic work flow included plasma immunodepletion, a standard procedure that remove albumin and IgG, the two most abundance plasma proteins, which would otherwise interfere MS ability to detect total plasma lipoproteome. The fractionated plasma lipoproteomic workflow included fractionation of plasma lipoprotein by sequential ultracentrifugation, which was evaluated by processing three aliquots of a plasma sample across three days (one per day) and had an overall technical precision (mean [SD]) of $27.90 \%$ (14.61).

We then compared proteomics analysis results of fractionated plasma lipoproteins and immunodepleted plasma in a case-control study of $5 \mathrm{AD}$ cases and 5 age and sex matched controls. The mean (SD) ages of the 5 $\mathrm{AD}$ cases and 5 controls were 80.8 (5.1) and 77.6 (3.6) years, respectively. Both the cases and controls included 4 males and 1 female (Table 1). Un-adjusted $\mathrm{p}$ values

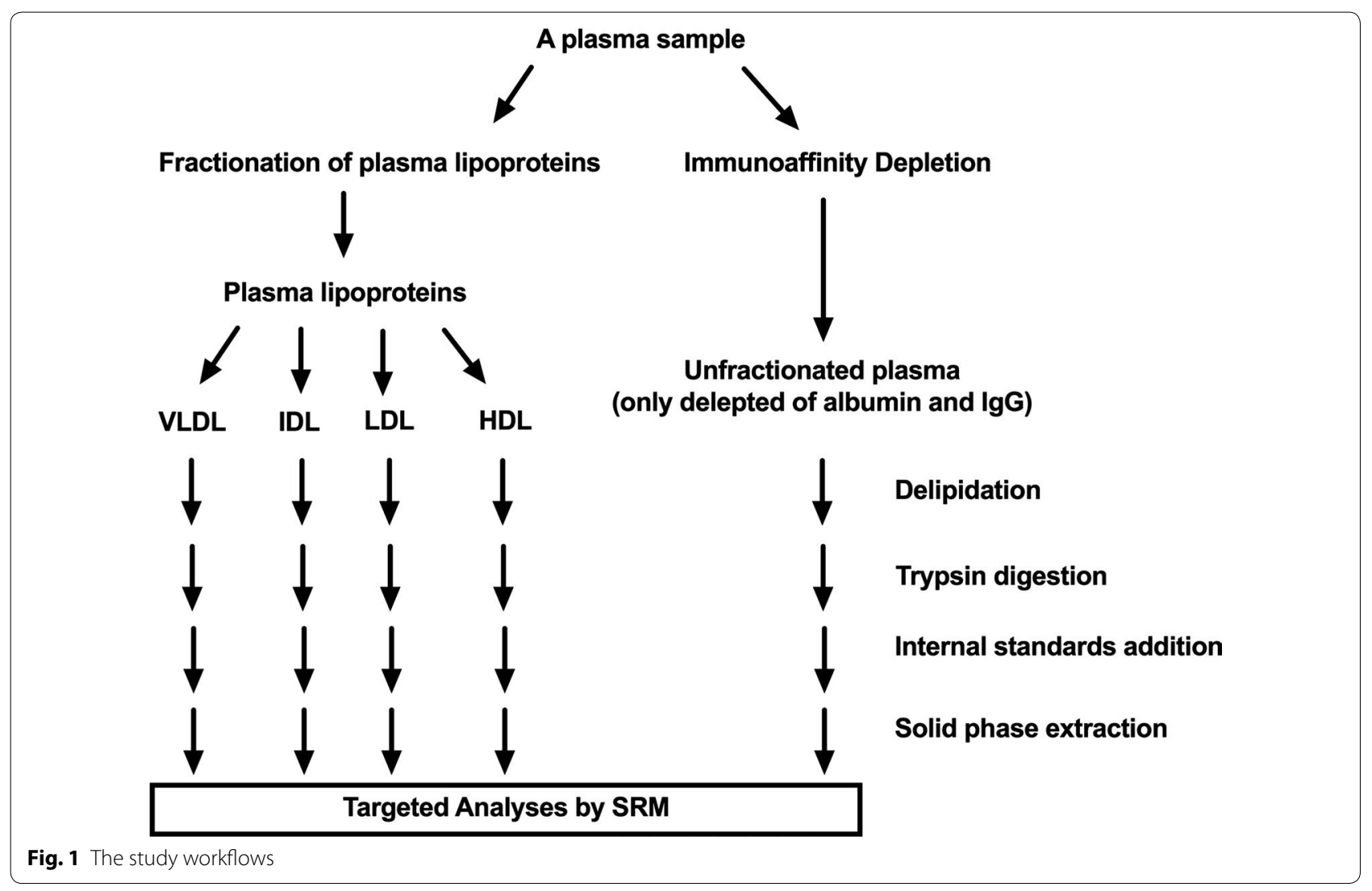


Table 1 Demographics of the case and control subjects

\begin{tabular}{llll}
\hline Characteristic & Controls & Cases & p value \\
\hline $\mathrm{n}$ & 5 & 5 & \\
Age (years) & $80.8 \pm 5.1$ & $77.6 \pm 3.6$ & 0.28 \\
Male $(\mathrm{n})$ & 4 & 4 & 1.00 \\
\hline
\end{tabular}

from two-sample t-tests and fold changes (calculated as ratios of mean relative level of a peptide between controls and AD cases) were used for the comparisons (Fig. $2 \mathrm{a}$ and b). None of the $\mathrm{p}$ values for the 120 peptides in immunodepleted plasma were lower than 0.05 , compared to 2,2 , and 4 peptides in VLDL, IDL, and LDL had p values less than 0.05 (Table 2). Furthermore, 6 peptides of the fold changes for the 120 peptides in immunodepleted plasma had fold changes larger than 1.05 or less than 0.95 , compared to 27, 32, 17, and 20 peptides in VLDL, IDL, LDL, and HDL. Since lower p values $(<0.05)$ and greater fold differences $(>1.05$ or $<0.95)$ indicated stronger evidence of a difference between the cases and controls, the overall comparisons showed that greater protein differences were identified in plasma lipoproteins than in immunodepleted plasma.

Table 2 included the 10 peptides measured in VLDL, IDL or LDL with two-sample t-tests un-adjusted $\mathrm{p}$ values less than 0.05 and their corresponding fold changes. These 10 peptides belong to 5 proteins, including 5
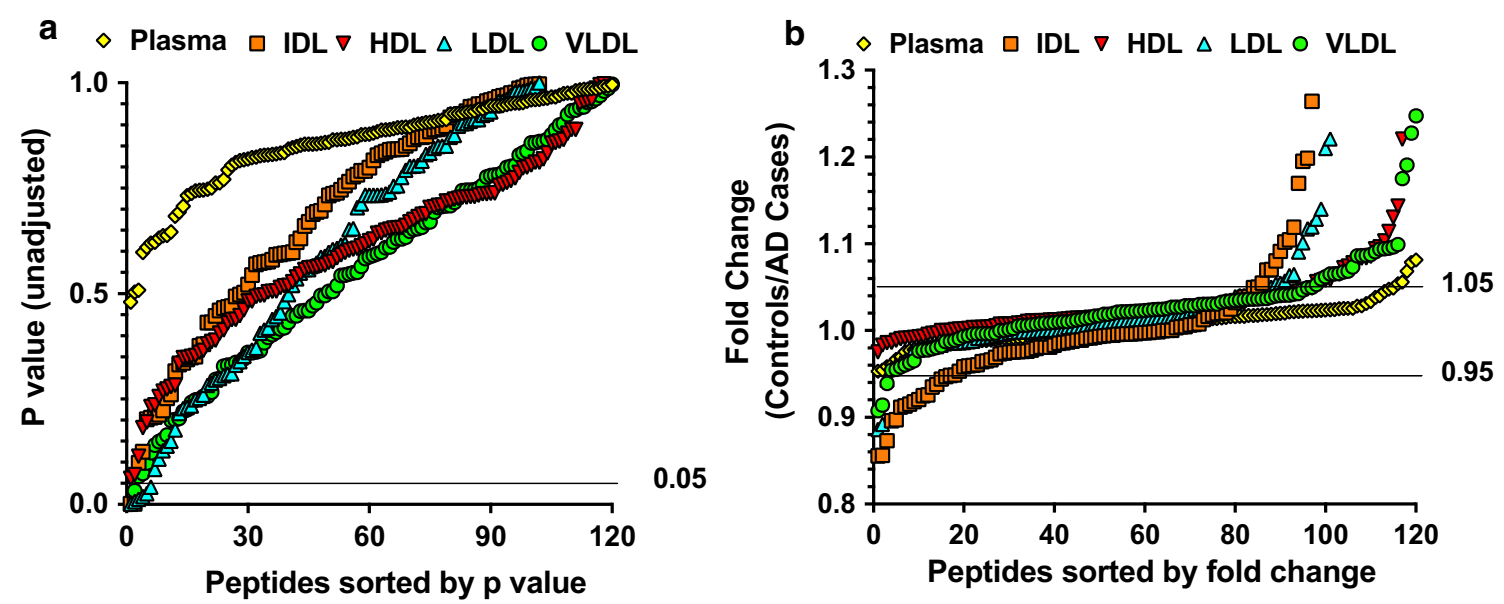

Fig. 2 Comparison of unadjusted p values (a) and fold changes (b) for 120 trypsin-digested peptides (from 79 proteins) in VLDL, IDL, LDL, and HDL fractionated from plasma and in immunodepleted plasma obtained from AD cases $(n=5)$ and matched cognitively unimpaired controls $(n=5)$. Peptide levels were measured using MS-based targeted proteomics. Unadjusted p values were obtained from two-sample t-tests of peptide levels, and ratios of mean peptide levels in the controls to AD cases were used to indicate fold change

Table 2 Top 10 proteins with the lowest unadjusted $p$ values across all plasma lipoprotein fractions

\begin{tabular}{|c|c|c|c|c|c|}
\hline $\begin{array}{l}\text { Plasma lipoprotein } \\
\text { fraction }\end{array}$ & Peptide & Protein & Unadjusted $p$ value & FDR adjusted $p$ value & $\begin{array}{l}\text { Fold-changes } \\
\text { (controls/AD } \\
\text { cases) }\end{array}$ \\
\hline VLDL & IHWESASLLR & $\mathrm{C} 3$ & $7.4987 \mathrm{E}-05$ & 0.009073469 & 1.25 \\
\hline IDL & TLDPER & C3 & 0.00116714 & 0.059597026 & 1.19 \\
\hline $\mathrm{IDL}$ & IHWESASLLR & $\mathrm{C} 3$ & 0.00116857 & 0.059597026 & 1.17 \\
\hline LDL & IHWESASLLR & $\mathrm{C} 3$ & 0.00061261 & 0.062486488 & 1.14 \\
\hline LDL & TLDPER & $\mathrm{C} 3$ & 0.00678427 & 0.345997683 & 1.21 \\
\hline LDL & GNYDAAQR & Serum amyloid A4 & 0.01222158 & 0.415533787 & 1.04 \\
\hline LDL & ALSNVEGFER & Integrin alpha 2B & 0.01827252 & 0.465949135 & 0.84 \\
\hline LDL & EALQGVGDMGR & Serum amyloid A4 & 0.02575496 & 0.52540128 & 1.06 \\
\hline LDL & VGYVSGWGR & Haptoglobin & 0.04077834 & 0.693231851 & 1.1 \\
\hline VLDL & TTSGIHPK & $\begin{array}{c}\text { chemokine (C-X-C } \\
\text { motif) ligand } 7\end{array}$ & 0.0324837 & 0.998795424 & 1.17 \\
\hline
\end{tabular}



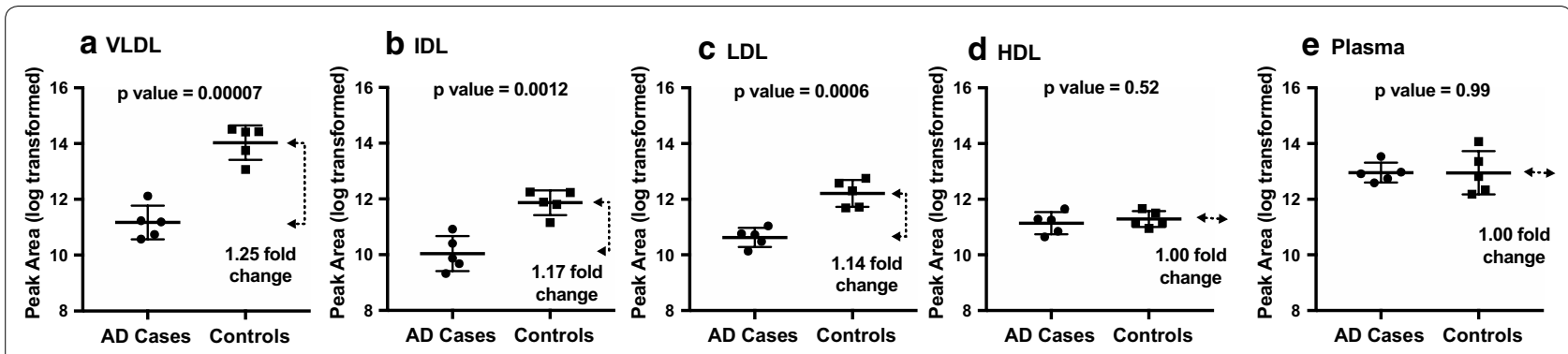

Fig. 3 Comparison of complement C3 peptide IHWESASLLR levels in VLDL, IDL, LDL, and HDL fractionated from plasma and in immunodepleted plasma obtained from AD cases $(n=5)$ and matched cognitively unimpaired controls $(n=5)$. Peptide levels were measured using MS-based targeted proteomics. Unadjusted $p$ values are displayed at the top of each plot, the middle lines indicate means, and the bottom and top lines indicate SD bars

\section{Table 3 Power of a future case control study at given effect sizes}

\begin{tabular}{lllll}
\hline $\mathbf{N}=\mathbf{3 0 / g r o u p}$ & & & & \\
\hline Effect size & 0.45 & 0.5 & 0.55 & 0.6 \\
Power* & 0.62 & 0.73 & 0.83 & 0.90
\end{tabular}

* At a significance level of 0.05 , after adjustment for 6 comparisons (assumed number of protein biomarkers) using the conservative Bonferroni method

peptides to complement C3. Figure 3 illustrated relative levels comparison of complement C3 peptide IHWESASLLR in VLDL, IDL, LDL, and HDL and in immunodepleted plasma. In contrast to no case-vs-control differences in IHWESASLLR when measured in HDL and in immunodepleted plasma (Fig. 3d, e), it had unadjusted $p$ values of $0.00007,0.00012$, and 0.0006 , respectively, and 1.25, 1.17, 1.14-fold changes, respectively, when measured in VLDL, IDL, and LDL (Fig. 3a, b, c). After pFDR adjustment, complement C3's peptide IHWESASLLR in VLDL remained statistically significant difference between the cases and controls (FDR adjusted $\mathrm{p}$ value $<0.05)$. From the statistical analysis results, we estimated a standard deviation of 0.58 for the log-transformed complement C3 IHWESASLLR levels in VLDL. Based on the estimated standard deviation, we computed the powers for a two-sample $t$ test to test the hypothesis of different means in log-transformed C3 IHWESASLLR levels in VLDL, for a planned future study with 30 cases and 30 controls. Table 3 presents the powers for a variety of values of effect size, with Bonferroni adjustment for six comparisons (assuming six protein biomarkers) and a family-wise Type I error rate of 0.05 .

\section{Discussion}

There have been studies using untargeted $[9,21]$ and targeted proteomics $[22,23]$ to investigate plasma lipoproteome in individual plasma lipoprotein fractions in cardiovascular, diabetes, and kidney diseases [10, 23-25].
To our knowledge, this study is the first to apply targeted proteomics to characterize plasma lipoproteome in $\mathrm{AD}$ and in plasma lipoprotein fractions beyond HDL. This study results suggest that the plasma lipoproteome when measured in plasma lipoprotein fractions (VLDL, IDL, LDL, and HDL) identifies more proteins with much stronger associations with $\mathrm{AD}$ when compared with analyses of total plasma lipoproteome in immunodepleted plasma.

This study especially observed complement C3 peptide IHWESASLLR's difference between the cases and controls. Complement $\mathrm{C} 3$ is a protein of the immune system and plays a central role in the activation of complement system. Complement C3b adherence is a key step in the removal from the bloodstream of pathogens and proteins recognized as foreign. Previous studies have shown inconsistent associations between plasma complement $\mathrm{C} 3$ and AD. The majority of research demonstrated a higher plasma complement $\mathrm{C} 3$ level correlated with more brain amyloid burden [26, 27] and less hippocampal volume [28] in sporadic AD [29] and mutation carriers of autosomal dominant form of AD [30]. However, a recent study showed a lower plasma complement C3 level in amnestic mild cognitive impairment compared to normal [31]. This study indicated that the level of complement C3 was lower in VLDL, IDL, and LDL in AD cases than in controls. Because complement $\mathrm{C} 3$ mediated mechanisms seem to play important roles in the clearance of circulating amyloid beta [32], the findings on lower plasma VLDL, IDL and LDL complement C3 levels in AD may suggest the role of plasma lipoprotein associated $C 3$ in $A \beta$ clearance via complement mechanisms.

Despite these proof-of-concept results, this study has several limitations. First of all, it is limited by its small sample size. However, complement C3 IHWESASLLR in VLDL had pFDR adjusted statistically significant $p$ value of 0.009 to distinguish the $5 \mathrm{AD}$ cases and 5 controls. Second, the cases and controls were obtained from 
different cohorts and therefore there may be inherent bias. However, the bias, if it exists, would have affected both the immunodepleted and fractionated approaches equally. Third, we did not collect extensive demographic and genetic (e.g., $A P O E$ genotypes) information on these subjects and medications that might have affected plasma lipoproteins. Fourth, even though the entire workflow including fractionation of plasma lipoproteins using ultracentrifugation is well-established in literature and has been used to investigate plasma lipoproteome in cardiovascular disease $[9,10,25]$, it is labor intensive. Future studies are needed to improve and automate the sample preparation workflow. Last but not the least, the $\mathrm{AD}$ cases were diagnosed based on clinical examination without amyloid deposition data. Because the context of use (COU) that we envision for proteins in plasma lipoproteins as biomarkers is to detect high likelihood of abnormal amyloid deposition in the brain of individuals who should be referred for amyloid neuroimaging to provide definitive measures (for either diagnostic or clinical trial enrollment purposes) [33], this proof-of-concept study results still need to be validated in a future case-control study of $\mathrm{AD}$ cases and controls with confirmed amyloid deposition data.

\section{Conclusions}

This study provides initial evidence supporting a novel concept that measurement of plasma lipoproteome in plasma lipoprotein fractions may increase the accuracy of plasma lipoproteome in diagnosing AD. Future investigations including larger validation studies are needed to test plasma lipoproteome in plasma lipoprotein fractions as potential biomarkers in $\mathrm{AD}$.

\section{Additional files}

Additional file 1. Supplementary methods.

Additional file 2: Table S1. The list of proteins and peptides included in the targeted SRM analysis.

\section{Authors' contributions}

DL developed the study concept and design, defined intellectual content, conducted literature research, analyzed the data, prepared the manuscript and is the guarantor of integrity of the entire study. FH conducted the experimental studies and acquired and analyzed the data. $Y Z$ helped with the targeted proteomics method and data acquisition. LZ analyzed the data. All authors read and approved the final manuscript.

\section{Author details}

${ }^{1}$ Department of Laboratory Medicine and Pathology, University of Minnesota, 420 Delaware Street SE, MMC 609, Minneapolis, MN 55455, USA. ${ }^{2}$ Masonic Cancer Center, University of Minnesota, Minneapolis, MN 55455, USA. ${ }^{3}$ Department of Biochemistry, Molecular Biology, and Biophysics, University of Minnesota, Minneapolis, MN 55455, USA. ${ }^{4}$ Department of Biostatistics, University of Minnesota, Minneapolis, MN 55455, USA. ${ }^{5}$ Department of Experimental and Clinical Pharmacology, University of Minnesota, Minneapolis, MN 55455, USA. ${ }^{6}$ School of Nursing, University of Minnesota, Minneapolis, MN 55455, USA.

\section{Acknowledgements}

We thank the FIT-AD Trials subjects and families for participating in the blood biomarker ancillary study. Our appreciation goes to Dr. Patric Clapshaw and Mr. Brian Wilbur from the Somolom Park (Burien, WA) who provided plasma samples for controls. Mass spectrometry was carried out in the Analytical Biochemistry Shared Resource of the Masonic Cancer Center, University of Minnesota, funded in part by Cancer Center Support Grant CA-077598. We thank Dr. Laura Parker's lab at the University of Minnesota for reference peptide synthesis.

\section{Competing interests}

The authors declare that they have no competing interests.

\section{Availability of data and materials}

The datasets used and/or analyzed during the current study are available from the corresponding author on reasonable request.

\section{Consent for publication \\ Not applicable.}

\section{Ethics approval and consent to participate}

This study was reviewed and approved by the University of Minnesota (UMN) Institutional Review Board.

\section{Funding}

This work was supported by a grant from the Alzheimer's Association (NIRG15-362393). The FIT-AD Trial was supported by the National Institute on Aging of the National Institutes of Health Award Number 1R01AG043392-01A1. All subject interviews and data collections occurred at the CTSI that was supported by the National Institutes of Health National Center for Advancing Translational Sciences of the National Institutes of Health Award Number UL1TR000114. None of the sponsors had any role in study design, data analysis, or reporting of the results. The content is solely the responsibility of the authors and does not necessarily represent the official views of the Alzheimer's Association and the National Institutes of Health. Dr. Li also receive research support from the NIH (R21 AG059068 and R01 AG059654).

\section{Publisher's Note}

Springer Nature remains neutral with regard to jurisdictional claims in published maps and institutional affiliations.

Received: 7 August 2018 Accepted: 15 September 2018

Published online: 20 September 2018

\section{References}

1. Albert MS, DeKosky ST, Dickson D, et al. The diagnosis of mild cognitive impairment due to Alzheimer's disease: recommendations from the National Institute on Aging-Alzheimer's Association workgroups on diagnostic guidelines for Alzheimer's disease. Alzheimer's Dement. 2011;7(3):270-9.

2. Sperling RA, Aisen PS, Beckett LA, et al. Toward defining the preclinical stages of Alzheimer's disease: recommendations from the National Institute on Aging-Alzheimer's Association workgroups on diagnostic guidelines for Alzheimer's disease. Alzheimer's Dement. 2011;7(3):280-92.

3. Gupta VB, Laws SM, Villemagne VL, et al. Plasma apolipoprotein E and Alzheimer disease risk: the AIBL study of aging. Neurology. 2011;76(12):1091-8.

4. Gupta VB, Doecke JD, Hone E, et al. Plasma apolipoprotein J as a potential biomarker for Alzheimer's disease: Australian Imaging, Biomarkers and Lifestyle study of aging. Alzheimers Dement (Amst). 2016;3:18-26.

5. Thambisetty M, Simmons A, Velayudhan L, et al. Association of plasma clusterin concentration with severity, pathology, and progression in Alzheimer disease. Arch Gen Psychiatry. 2010;67(7):739-48. 
6. Song F, Poljak A, Crawford J, et al. Plasma apolipoprotein levels are associated with cognitive status and decline in a community cohort of older individuals. PLoS ONE. 2012;7(6):e34078.

7. Rasmussen KL, Tybjaerg-Hansen A, Nordestgaard BG, Frikke-Schmidt R. Plasma levels of apolipoprotein $\mathrm{E}$ and risk of dementia in the general population. Ann Neurol. 2015;77(2):301-11.

8. Schrijvers EM, Koudstaal PJ, Hofman A, Breteler MM. Plasma clusterin and the risk of Alzheimer disease. JAMA. 2011;305(13):1322-6.

9. Vaisar T, Pennathur S, Green PS, et al. Shotgun proteomics implicates protease inhibition and complement activation in the antiinflammatory properties of HDL. J Clin Invest. 2007;117(3):746-56.

10. Vaisar T, Tang C, Babenko I, et al. Inflammatory remodeling of the HDL proteome impairs cholesterol efflux capacity. J Lipid Res. 2015;56(8):1519-30

11. Carr SA, Abbatiello SE, Ackermann BL, et al. Targeted peptide measurements in biology and medicine: best practices for mass spectrometrybased assay development using a fit-for-purpose approach. Mol Cell Proteomics. 2014;13(3):907-17.

12. Addona TA, Abbatiello SE, Schilling B, et al. Multi-site assessment of the precision and reproducibility of multiple reaction monitoring-based measurements of proteins in plasma. Nat Biotechnol. 2009;27(7):633-41.

13. Yu F, Bronas UG, Konety S, et al. Effects of aerobic exercise on cognition and hippocampal volume in Alzheimer's disease: study protocol of a randomized controlled trial (The FIT-AD trial). Trials. 2014;15:394.

14. Brousseau T, Clavey V, Bard JM, Fruchart JC. Sequential ultracentrifugation micromethod for separation of serum lipoproteins and assays of lipids, apolipoproteins, and lipoprotein particles. Clin Chem. 1993;39(6):960-4.

15. Godzien J, Ciborowski M, Armitage EG, et al. A single in-vial dual extraction strategy for the simultaneous lipidomics and proteomics analysis of HDL and LDL fractions. J Proteome Res. 2016;15(6):1762-75.

16. MacLean B, Tomazela DM, Shulman N, et al. Skyline: an open source document editor for creating and analyzing targeted proteomics experiments. Bioinformatics. 2010;26(7):966-8.

17. Storey JD. A direct approach to false discovery rates. J R Stat Soc Ser B (Stat Methodol). 2002;64(3):479-98.

18. Kirkpatrick DS, Gerber SA, Gygi SP. The absolute quantification strategy: a general procedure for the quantification of proteins and post-translational modifications. Methods. 2005:35(3):265-73.

19. Keshishian H, Addona T, Burgess M, Kuhn E, Carr SA. Quantitative, multiplexed assays for low abundance proteins in plasma by targeted mass spectrometry and stable isotope dilution. Mol Cell Proteomics. 2007:6(12):2212-29.

20. Li M, Gray W, Zhang H, et al. Comparative shotgun proteomics using spectral count data and quasi-likelihood modeling. J Proteome Res. 2010;9(8):4295.
21. Dashty M, Motazacker MM, Levels J, et al. Proteome of human plasma very low-density lipoprotein and low-density lipoprotein exhibits a link with coagulation and lipid metabolism. Thromb Haemost. 2014;111(3):518-30.

22. Ronsein GE, Pamir N, von Haller PD, et al. Parallel reaction monitoring (PRM) and selected reaction monitoring (SRM) exhibit comparable linearity, dynamic range and precision for targeted quantitative HDL proteomics. J Proteomics. 2015;113:388-99.

23. Hoofnagle AN, Wu M, Gosmanova AK, et al. Low clusterin levels in high-density lipoprotein associate with insulin resistance, obesity, and dyslipoproteinemia. Arterioscler Thromb Vasc Biol. 2010;30(12):2528-34

24. Shao B, de Boer I, Tang C, et al. A cluster of proteins implicated in kidney disease is increased in high-density lipoprotein isolated from hemodialysis subjects. J Proteome Res. 2015;14(7):2792-806.

25. Ronsein GE, Reyes-Soffer G, He Y, Oda M, Ginsberg H, Heinecke JW. Targeted proteomics identifies paraoxonase/arylesterase 1 (PON1) and apolipoprotein Cs as potential risk factors for hypoalphalipoproteinemia in diabetic subjects treated with fenofibrate and rosiglitazone. Mol Cell Proteomics. 2016;15(3):1083-93.

26. Thambisetty M, Tripaldi R, Riddoch-Contreras J, et al. Proteome-based plasma markers of brain amyloid- $\beta$ deposition in non-demented older individuals. J Alzheimers Dis. 2010;22(4):1099-109.

27. Kiddle SJ, Thambisetty M, Simmons A, et al. Plasma based markers of [11C] PiB-PET brain amyloid burden. PLoS ONE. 2012;7(9):e44260.

28. Thambisetty M, Simmons A, Velayudhan L, et al. Association of plasma clusterin concentration with severity, pathology, and progression in Alzheimer disease. Arch Gen Psychiatry. 2010;67(7):739-48.

29. Giometto B, Argentiero V, Sanson F, Ongaro G, Tavolato B. Acute-phase proteins in Alzheimer's disease. Eur Neurol. 1988:28(1):30-3.

30. Muenchhoff J, Poljak A, Thalamuthu A, et al. Changes in the plasma proteome at asymptomatic and symptomatic stages of autosomal dominant Alzheimer's disease. Sci Rep. 2016;6:29078.

31. Uchida K, Shan L, Suzuki H, et al. Amyloid- $\beta$ sequester proteins as bloodbased biomarkers of cognitive decline. Alzheimers Dement (Amst). 2015:1(2):270-80.

32. Rogers J, Li R, Mastroeni $D$, et al. Peripheral clearance of amyloid $\beta$ peptide by complement C3-dependent adherence to erythrocytes. Neurobiol Aging. 2006;27(12):1733-9.

33. O'Bryant SE, Mielke MM, Rissman RA, et al. Blood-based biomarkers in Alzheimer disease: current state of the science and a novel collaborative paradigm for advancing from discovery to clinic. Alzheimer's Dement J Alzheimer's Assoc. 2017;13(1):45-58
Ready to submit your research? Choose BMC and benefit from:

- fast, convenient online submission

- thorough peer review by experienced researchers in your field

- rapid publication on acceptance

- support for research data, including large and complex data types

- gold Open Access which fosters wider collaboration and increased citations

- maximum visibility for your research: over 100M website views per year

At BMC, research is always in progress.

Learn more biomedcentral.com/submissions 